\title{
NUMERICAL AND EXPERIMENTAL ANALYSIS OF A SEGMENTED WIND TURBINE BLADE UNDER ASSEMBLING LOAD EFFECTS
}

\author{
Majdi Yangui, Slim Bouaziz, Mohamed Taktak \\ Mechanics, Modelling and Production Laboratory (LA2MP), National School of Engineers of Sfax, University of Sfax, \\ Tunisia; e-mail: yanguimajdi@gmail.com; slim.bouaziz1@gmail.com; mohamed.taktak@fss.rnu.tn \\ Vincent Debut, Jose Antunes \\ Centro de Ciências e Tecnologias Nucleares, Instituto Superior Técnico, Universidade de Lisboa, Portugal \\ e-mail: vincentdebut@ctn.tecnico.ulisboa.pt; jantunes@ctn.tecnico.ulisboa.pt \\ MOHAMED HADDAR \\ Mechanics, Modelling and Production Laboratory (LA2MP), National School of Engineers of Sfax, University of Sfax, \\ Tunisia; e-mail: mohamed.haddar@enis.rnu.tn
}

\begin{abstract}
In this paper, numerical and experimental modal analysis of a segmented wind turbine blade assembled with a steel threaded shaft and a nut are presented. The blade segments are built by a 3D printer using ABS material. The experimental modal parameters identification has been achieved using the Eigen system Realization Algorithm (ERA) method for different values of the blade segments assembly force caused by the nut tightening torque. Furthermore, a three dimensional finite element model has been built using DTK18 three node triangular shell elements in order to model the blade and the threaded shaft structure, taking into account the additional stiffness caused by the nut tightening torque. This study covers the blade segments assembly force effects on the rotating blade vibration characteristics. The numerical model is adjusted and validated by the identified experimental results. This work highlights the significant variation of the natural frequencies of the segmented wind turbine blade by the assembling load of the segments versus blade rotating speed.
\end{abstract}

Keywords: segmented wind turbine blade, experimental modal analysis, shell element modeling, assembling load

\section{Introduction}

In recent years, due to the dramatic increase of energy demands, the concerns about environmental pollution resulting from energy extraction have made development of renewable energy more and more important for a sustainable future. Wind energy is considered as one of the most profitable renewable energy sources. To extract more energy from wind, manufacturers aim at increasing the wind turbine blade size, which led many researchers to investigate emerging problems like vibration, in order to reduce wind turbine component failures and extend their life cycle. Modal or resonance frequencies must be investigated during the blade design process where the blade natural frequencies must be well above the wind turbine working frequencies, see McKittrick et al. (2001). Maalawi and Negm (2002) employed the Euler Bernoulli beam theory and presented an optimization model for the design of a typical wind turbine blade structure in order to make an exact placement of natural frequencies of the blade to avoid resonance. Therefore, wind turbine blade modal analysis was established by experimental and theoretical studies. For instance, an experimental modal analysis of a wind turbine using accelerometers was performed by Molenaar (2003). The identified natural frequencies were used to validate the presented wind turbine modeling approach. To improve the calibration process of the blade 
structural model parameters, Griffith et al. (2009) developed a hybrid calibration approach using experiments.

The FEM is the most widely used in the wind turbine blade development for investigating their dynamic behavior. The Beam Element Method, in which the blade is idealized as a cantilever beam have been used in many researches by dint of its several merits such as simplicity of formulation. Park et al. (2010) proposed an analytical procedure based on the Beam Element Method to examine blade natural frequencies in relation with its operating speed. Sheibani and Akbari (2015) developed a blade beam finite element model with an arbitrary cross section, ignoring the effects of rotational speed and pitch angle on the natural frequencies and the mode shapes. Several researchers tried to verify the finite element model experimentally to ensure the model validity. Actually, a scaled-down wind turbine blade model has been built to validate the numerical model by testing the built model and comparing the obtained experimental results with those determined by the numerical study. Tartibu et al. (2012) represented the wind turbine blade by some simplified shapes of a stepped beam to establish experimental and numerical modal analyses. Some discrepancies were observed for highest frequencies between the measured and the computed natural frequencies. Sami et al. (2014) extracted the fundamental flapwise and edgewise modal frequencies of a composite wind turbine blade using the Finite Element Method. The extracted frequencies were validated experimentally from modal testing using an electrodynamics shaker. Dhar (2006) developed a wind turbine model using Finite Element Method and proposed a methodology to design a small-scale test set-up of the full-scale wind turbine to reach structural invariants which were used to design structural components of a wind turbine. The most common method to measure vibration is to attach accelerometers to the blade and tap it with a hammer or excite it with a mechanical shaker. Experimental modal analysis of a 19.1 meter wind turbine blade was established by Larsen et al. (2002) to determine the blade natural frequencies, damping and mode shapes. It was also stated that there was a good agreement between the obtained results from the experimental work and those obtained by the FEM analysis. Abdulaziz et al. (2015) applied the Buckingham $\pi$-Theorem to develop an approach in which measurements and analysis of a scaled-down model can be used to predict the performance of full-scale wind turbine blades. The obtained results were used to predict and validate numerical solutions using ANSYS software of the full-scale blade. White dealing with an object with small mass, mass of the accelerometer changes resonant frequencies of the tested scaled-down blade in which this method would be inappropriate. Therefore, modal tests were performed by Kim et al. (2011) using the embedded fiber Bragg grating (FBG) sensors and the laser Doppler Vibrometer to investigate dynamic characteristics of a wind turbine blade. The tested blade was $1 / 23$ scale of $750 \mathrm{~kW}$ blade. Natural frequencies obtained from FBG sensors were found to be consistent with those from the laser Doppler Vibrometer. Ha et al. (2015) used the optical deformation measurement technique called Digital Image Correlation (DIC) to measure the natural frequencies, damping ratios and mode shapes of a blade excited by a shaker. Due to geometricas complexity of the wind turbine blade, a precise numerical model of the blade requires the use of shell elements rather than beam elements. Bayoumy et al. (2013) applied the absolute nodal thin plate element to model the complex shape of the wind turbine blade structure, to show the transient response of the blade due to gravitational and aerodynamics forces. Kang et al. (2014) developed a geometrically exact shell element for a rotorcraft based on assumptions of arbitrarily large displacements and rotations and small strain. The shell finite elements were compared with the beam element for the modeling of three typical blade structures. Modal analysis was established by Branner et al. (2007) using the FEM software Nastran. The wind turbine blade FEM model comprised 8-node shell elements. The FEM model was updated and validated against measurement results for the non rotating blade, identified by means of experimental modal analysis. To reduce the blade manufacturing and transport costs, a new approach was proposed to decompose the blade into several parts. Many segmentation 
techniques were proposed by Saldanha et al. (2013) and Broehl (2014). Nevertheless, the development of segmented blades remains an engineering problem and a tough challenge. Most of the work related to segmentation of wind turbine blades, by Bhat et al. (2015a,b) and Saldanha et al. (2013), shows that the natural frequency and static displacement versus the blade length can be considered as the primary parameters to design a segmented wind turbine. Yangui et al. (2016) studied the dynamic behavior of a segmented wind turbine blade using the three node triangular shell element DKT18. To validate the accuracy and reliability of the developed model, the obtained numerical results were compared to benchmark problems and modal analysis using ANSYS software. Several researchers tried to develop a numerical model to study the dynamic behavior of a wind turbine blade taking into account several external effects such as aerodynamic load, gyroscopic and rotation speed effects, see Hamdi et al. (2014). However, they ignored the assembly effort of the segments ehich must be studied in priority during design of the segmented blade.

In the present work, an attempt has been made to address this requirement by investigating natural frequencies and mode shapes of a segmented horizontal axis wind turbine blade subjected to the assembling load. Experimental modal analysis of a scaled-down segmented blade, assembled by a thread shaft and a nut has been performed using the laser Doppler Vibrometer. The ERA method is used to identify the blade modal parameters, i.e. natural frequencies and damping. The three node triangular shell element DKT18 is adopted in this paper to model the segmented blade and the thread shaft structure. The assembling load effects are assumed to concentrate in the thread shaft, seeing that its section is very small compared to the blade segments section. Displacements between segments are also neglected in the blade modeling. The developed FEM model parameters have been adjusted by the obtained experimental results to highlight the significant influence of the assembling load produced by the tightening torque versus the rotating speed on the natural frequencies of the wind turbine blade.

This paper is structured as follows. In Section 2, the assembled blade numerical model is presented. Section 3 is dedicated to the measuring system and the modal identification procedure. The experimental results are discussed in Section 4 to adjust and validate the developed numerical model. In the conclusions Section, some final reflections are raised.

\section{Blade numerical model}

In this Section, the three node triangular shell element DTK18 is used to develop the wind turbine blade model. It consists of five segments assembled together with a steel threaded shaft, as demonstrated in Fig. 1.

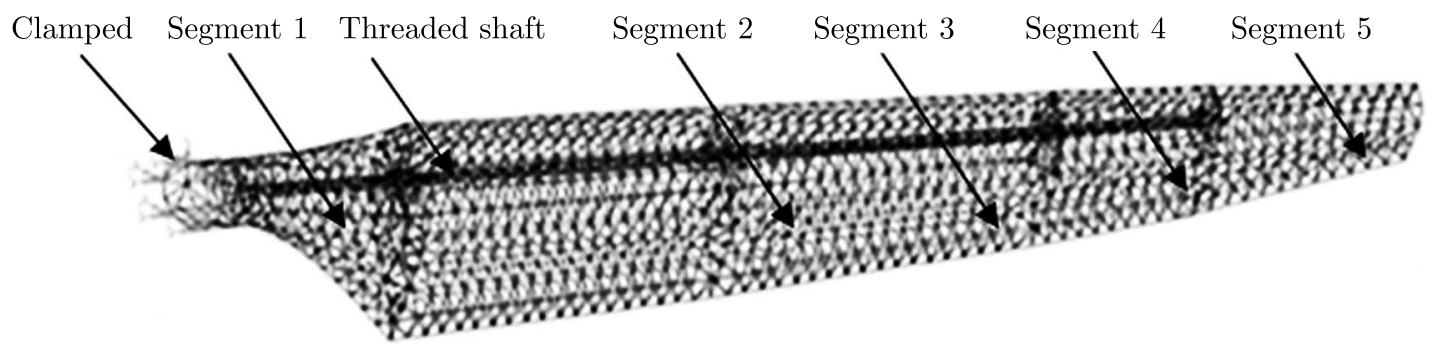

Fig. 1. Segmented wind turbine blade model

For rotating blades modeled by three nodes triangular shell elements, it has been demonstrated in previous works (Yangui et al., 2016) that the blade equation of motion can be written as

$$
\mathbf{M} \ddot{\mathbf{q}}+\mathbf{C} \dot{\mathbf{q}}+\left(\mathbf{K}_{e}+\mathbf{K}_{R}\right) \mathbf{q}=\mathbf{F}
$$


where $\mathbf{M}, \mathbf{C}, \mathbf{K}_{e}, \mathbf{K}_{R}$, and $\mathbf{F}$ are the global mass matrix, damping matrix, elastic stiffness matrix, centrifugal stiffness matrix and the global force vector, respectively.

Considering the presence of the tightening torque applied by the nut to assemble the blade segments, an additional strain energy increases the blade structure rigidity. Logically, the same solicitation, i.e. traction, will be applied by blade rotation and the tightening torque on the threaded shaft. Thus, this additional stiffness matrix may be assumed to have the same form of the centrifugal stiffness matrix, proportional to the nut tightening torque and depending on threaded shaft geometry.

The global tightening torque stiffness matrix $\mathbf{K}_{S}$ can be formulated as

$$
\mathbf{K}_{S}(i, j)=\frac{C_{s}}{R_{s} L_{s}} T_{p} \frac{\mathbf{K}_{R}(i, j)}{\left|\mathbf{K}_{R}(i, j)\right|}
$$

where $C_{s}, R_{s}$, and $T_{p}$ are, respectively, the tightening torque, threaded shaft radius and a proportional coefficient that will be empirically determined.

The resulting equations of motion are obtained as

$$
\mathbf{M} \ddot{\mathbf{q}}+\mathbf{C} \dot{\mathbf{q}}+\left(\mathbf{K}_{e}+\mathbf{K}_{R}+\mathbf{K}_{S}\right) \mathbf{q}=\mathbf{F}
$$

\section{Experimental analysis}

\subsection{Experimental procedure}

The 3D printing technology has been used to manufacture the blade segments. Teeth connected with holes in the segments interfaces were designed to prevent relative displacements between the segments. Thus, friction effects between the segments are neglected. The measuring system is shown in Fig. 2, which consists of an impact hammer to excite the blade structure, laser Vibrometer, charge amplifier, and a data acquisition system with a computer to process and display signals.

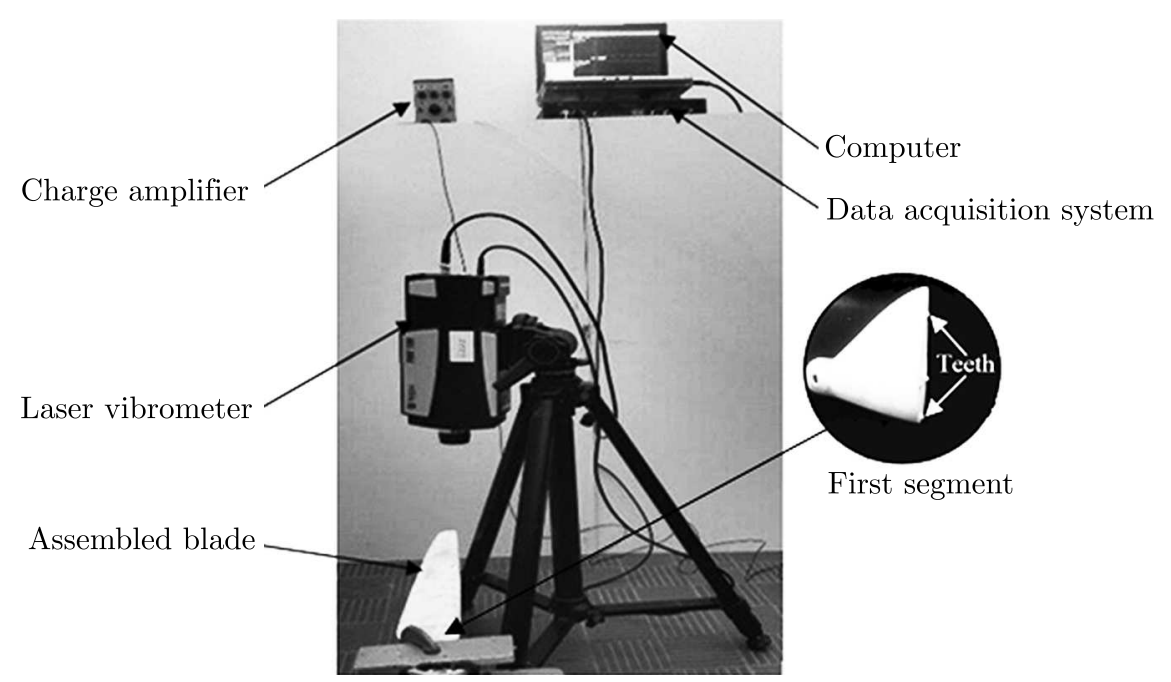

Fig. 2. Test stand for the assembled blade

To localize the measuring and excitation points, the blade has been discretized into 32 measuring points. In the third point, the blade is excited along the vertical direction (flap direction) and the horizontal direction (edge direction), as shown in Fig. 3. The vertical motion at all localized points is measured using the laser Vibrometer. 

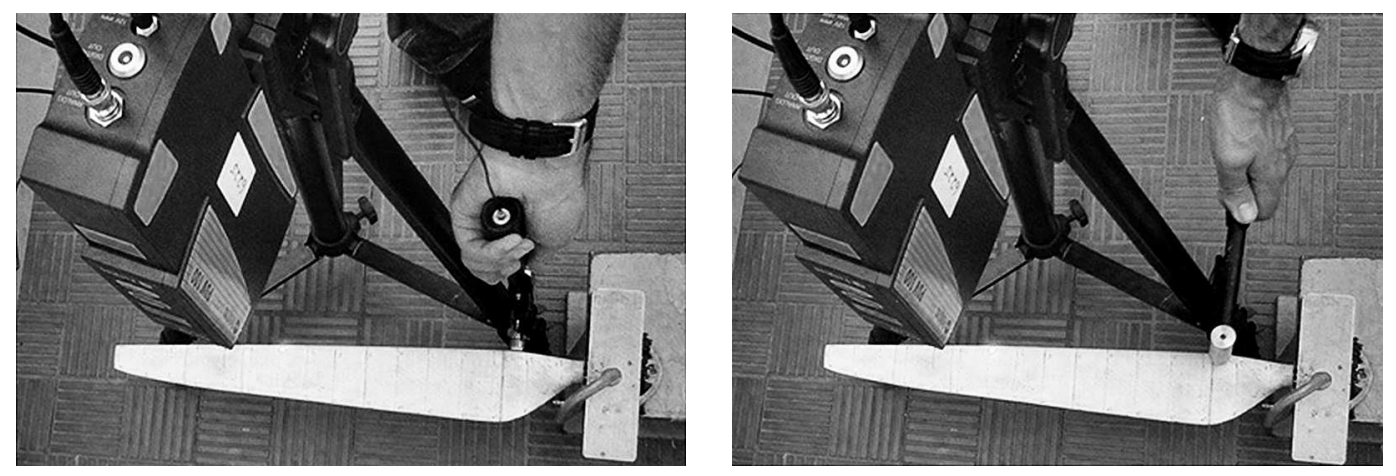

Fig. 3. Horizontal and vertical blade excitation

\subsection{Analysis procedure}

A schematic representation of the computation and validation process is shown in Fig. 4. The process starts from the time data of the excitation force $F(t)$ and the velocity response $V(t)$ to which the FFT is applied in order to determine the measured Frequency Response Functions (FRF) $H_{m e}(f)$. The Eigen system Realization Algorithm (ERA) identification method is used to find the system poles and residues to identify natural frequencies $\omega_{i}$, damping ratios $\xi_{i}$ and vibration mode shapes $\Phi_{i}$.

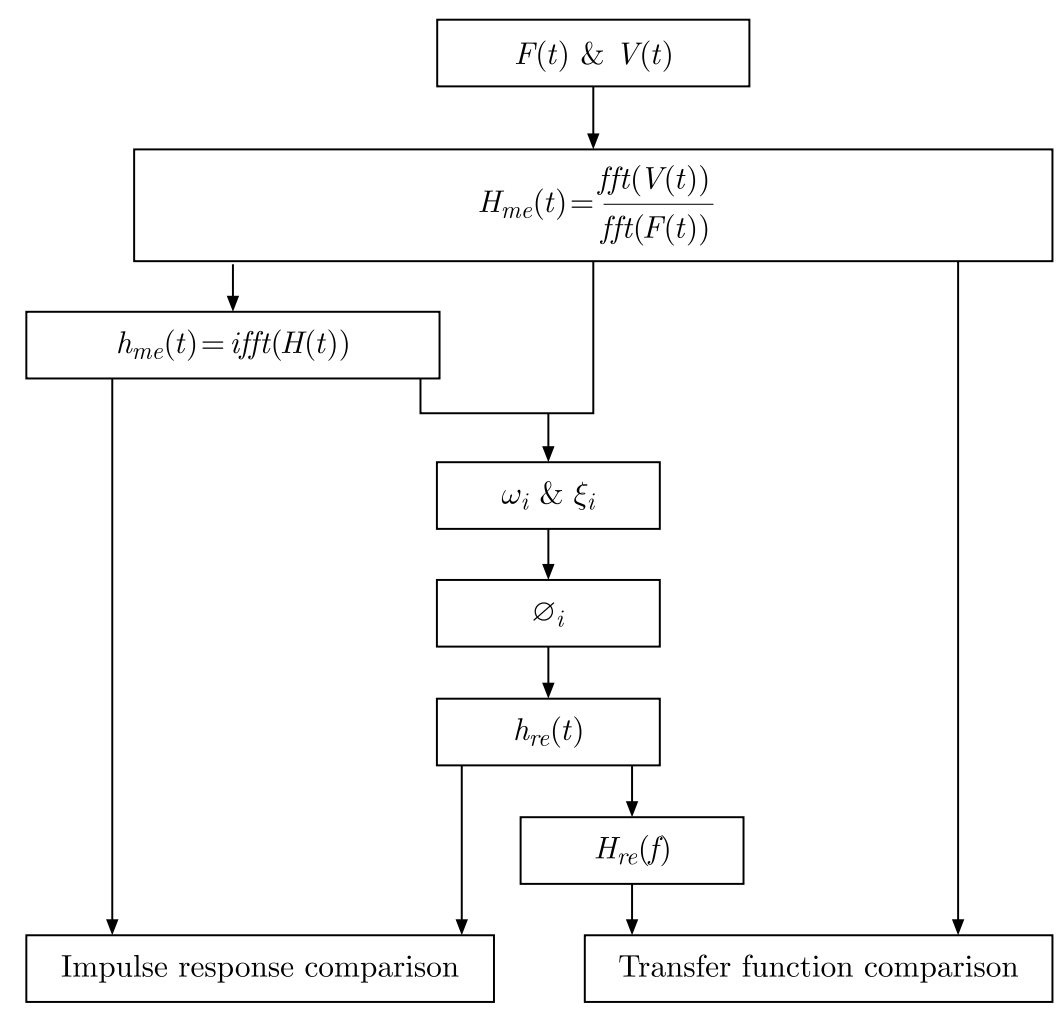

Fig. 4. Computational and validation process scheme

The reconstructed impulsion response $h_{r e}$ is determined according to the number of mode $N$ by the equation

$$
h_{r e}(t)=\sum_{i=1}^{N} \Phi_{i} \mathrm{e}^{\lambda_{i} t}
$$


where the eigenvalues $\lambda_{i}$ are written as

$$
\lambda_{i}=-\omega_{i} \xi_{i} \pm \mathrm{j} \omega_{i} \sqrt{1-\xi_{i}^{2}}
$$

The identified modal parameter validation is based on the comparison between the measured and the reconstructed impulse responses as well as transfer functions.

\section{Results and discussion}

\subsection{Experimental modal parameter identification}

The presented analysis procedure has been applied to the 32 measured signals as regard to the vertical excitation. Figure 5 shows the measured excitation force and velocity response of the seventh node.
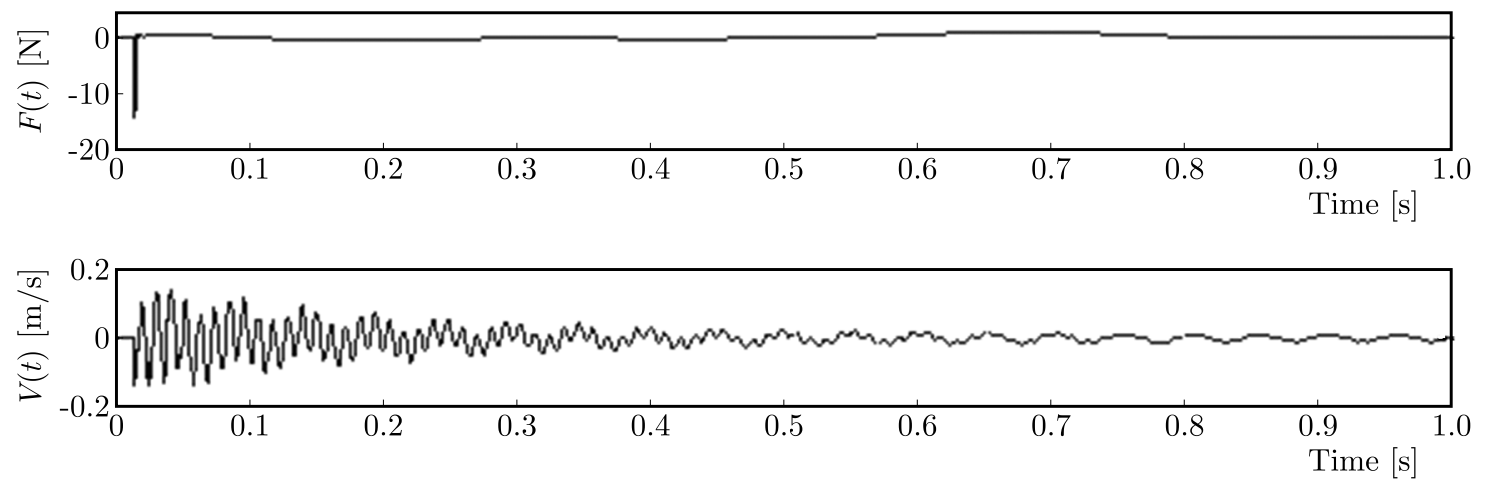

Fig. 5. Excitation force and the seventh node velocity response

Using the measured signals, the transfer function in addition to the impulse response has been determined, Fig. 6 .
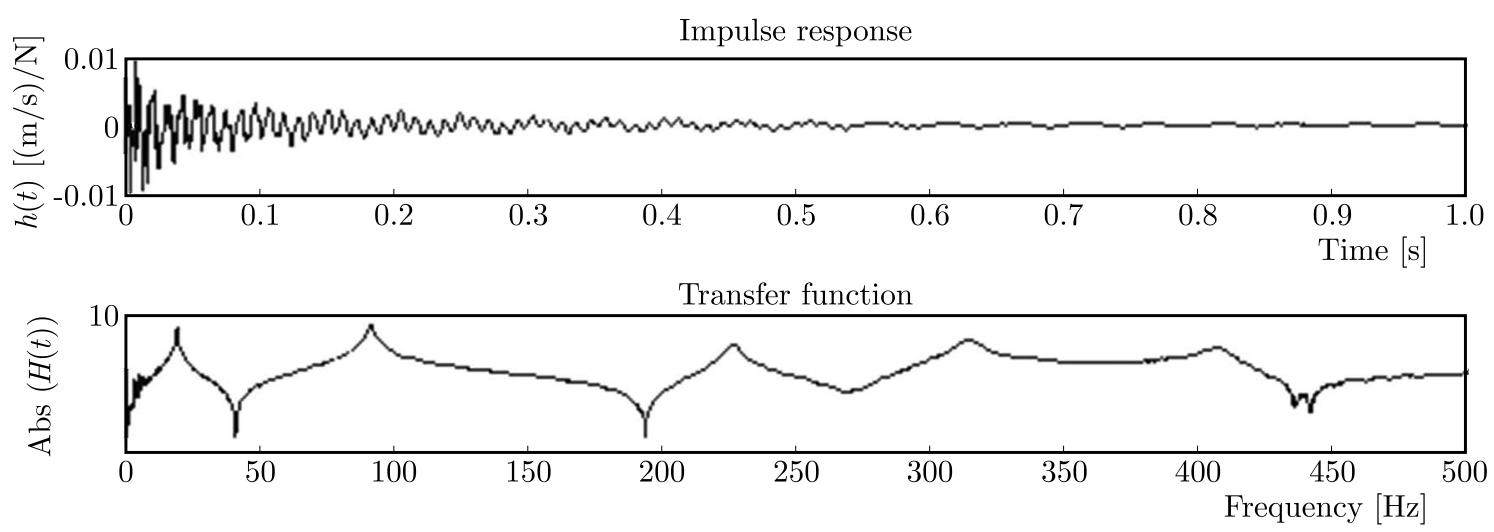

Fig. 6. Seventh node transfer function and impulse response

Table 1 presents the first five natural frequencies and damping ratios identified using the ERA method.

For each of the 32 nodes, the reconstructed impulse response and transfer function is determined and re-plotted with those obtained from measurement to validate the identified modal parameter. Figure 7 shows some of the measured and reconstructed fitted curves.

An acceptable agreement is obtained between the measured and the reconstructed impulse responses as well as the transfer functions. So, the identified modal parameters have been validated. 
(a)

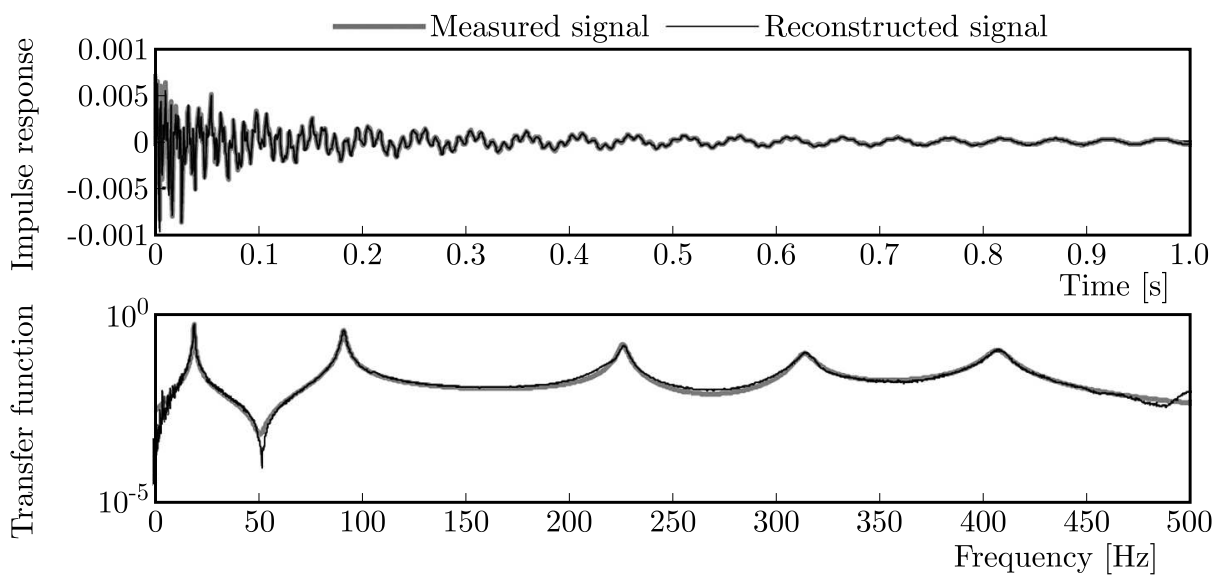

(b)
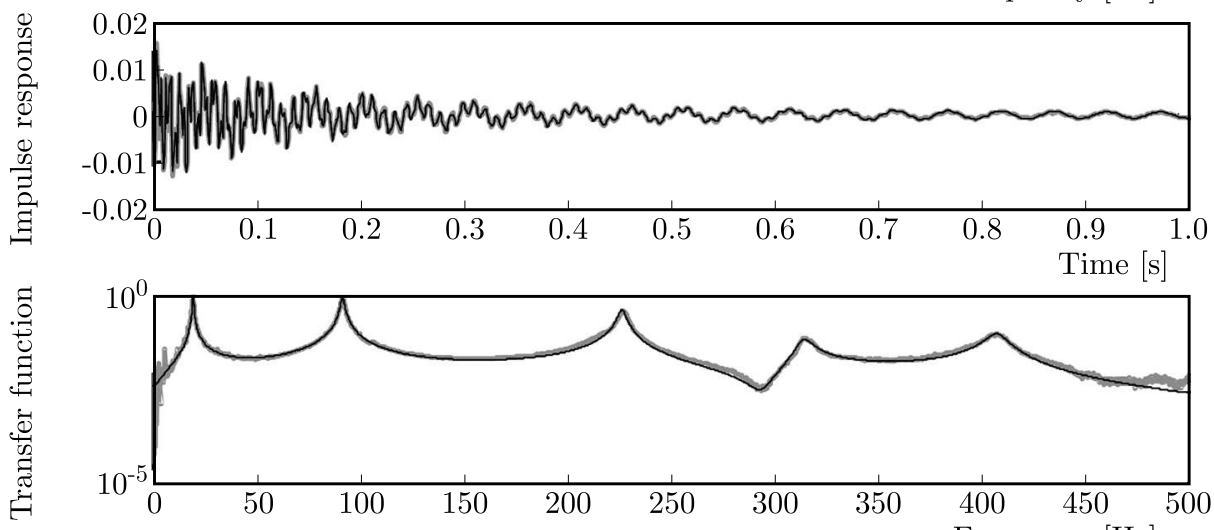

(c)

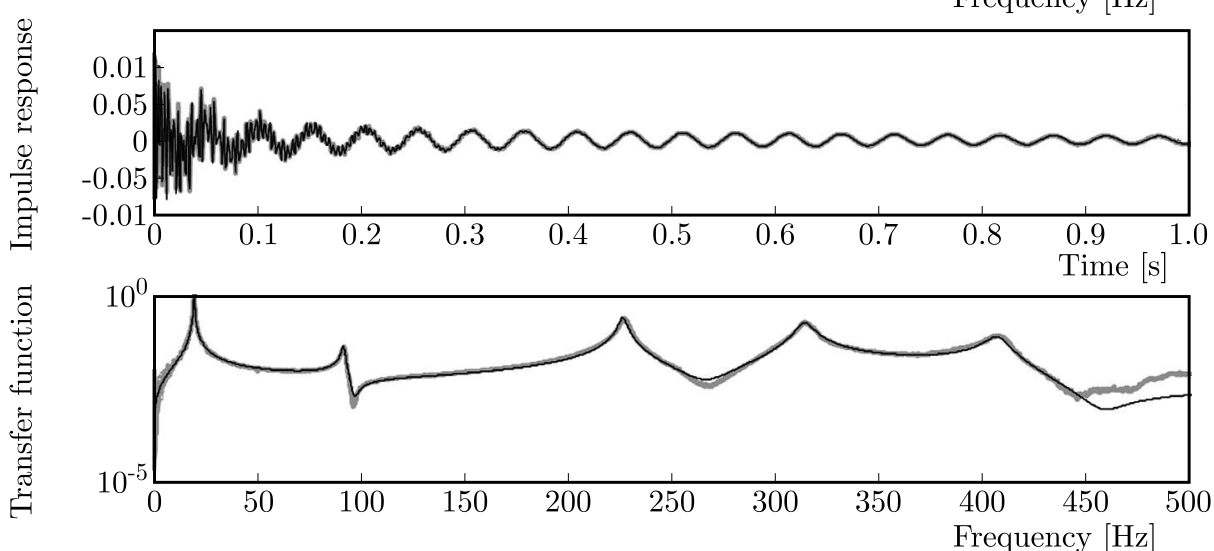

(d)
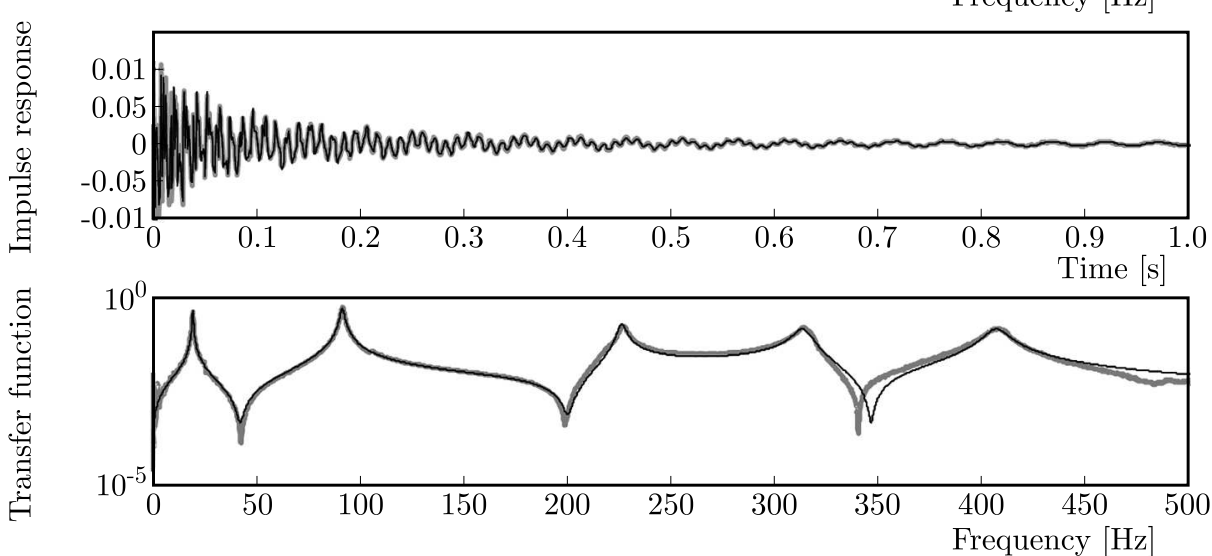

Fig. 7. Measured and reconstructed impulse responses and transfer functions: (a) Node 9, (b) Node 15, (c) Node 21, (d) Node 26 
Table 1. The identified natural frequencies and damping ratios

\begin{tabular}{|c|c|c|c|c|c|}
\hline & Mode 1 & Mode 2 & Mode 3 & Mode 4 & Mode 5 \\
\hline \hline$\omega[\mathrm{Hz}]$ & 19.5 & 95.7 & 226.5 & 314.3 & 407.6 \\
\hline$\xi[\%]$ & 1.08 & 0.93 & 0.75 & 1.14 & 1.19 \\
\hline
\end{tabular}

\subsection{Experimental mode shape identification}

To estimate the blade mode shape for each identified natural frequency, the previous process is repeated regarding the horizontal excitation direction. Figure 8 shows the transfer functions of the measured signals in the seventh node with respect to the excitation direction.

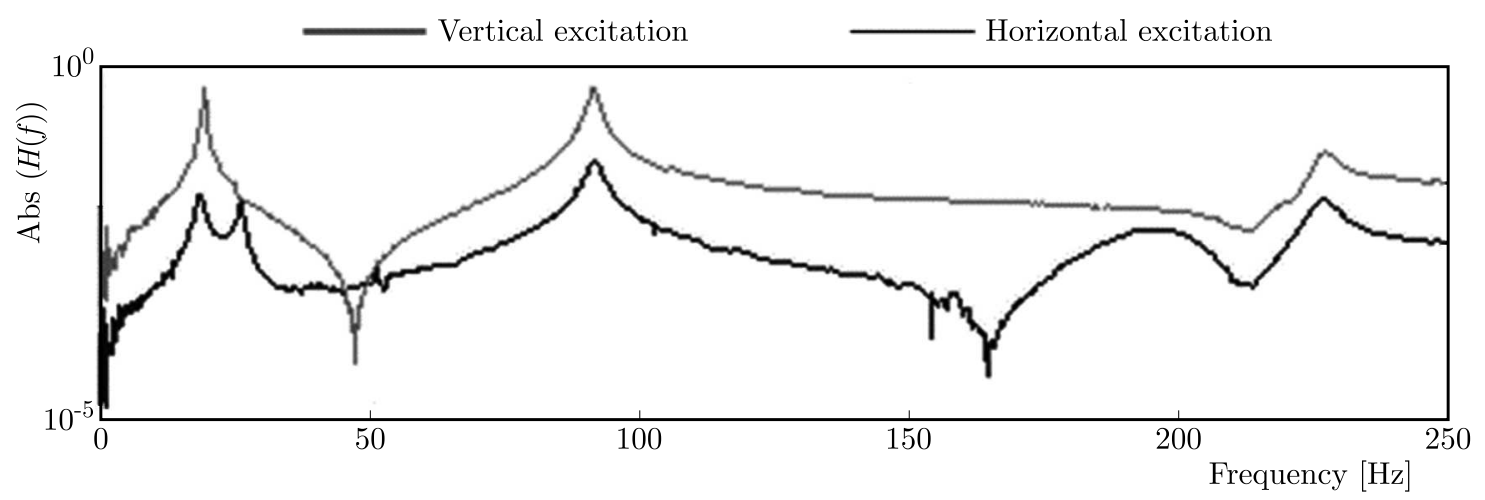

Fig. 8. Vertical and horizontal excitation transfer functions

Lower than $250 \mathrm{~Hz}$, two natural frequencies are more clearly observed from the transfer function of the horizontal excitation than from the vertical excitation. Table 2 presents the identified natural frequencies of the measured signals in the seventh node with respect to the horizontal excitation direction, using the ERA method.

Table 2. The identified natural frequencies with respect to the horizontal excitation

\begin{tabular}{|c|c|c|c|c|c|}
\hline Mode order & Mode 1 & Mode 2 & Mode 3 & Mode 4 & Mode 5 \\
\hline \hline$F[\mathrm{~Hz}]$ & 19.4 & 27.2 & 95.8 & 194.8 & 226.4 \\
\hline
\end{tabular}

Therefore, the natural frequencies determined by the vertical excitation present the blade flapwise or torsional mode. The other two mode shapes present the blade edgewise or torsional mode. The identified eigenvectors have been normalized in order to plot the blade mode shape as shown in Fig. 9.

\subsection{Mechanical characteristics adjustment}

To adjust the mechanical characteristics of the numerical model corresponding to the printed 3D model, an initial frequency analysis has been carried out in which the contacts between the blade segments are assured by teeth insertion in holes and conserved by the nut without applying the assembling preload to avoid tightening torque effects. The blade has length $L=500 \mathrm{~mm}$ and thickness $h=3 \mathrm{~mm}$. The material blade segment properties are $E=2.4 \mathrm{GPa}, \nu=0.38$ and $\rho=1140 \mathrm{~kg} / \mathrm{m}^{3}$. The threaded shaft material properties are $E=210 \mathrm{GPa}, \nu=0.3$ and $\rho=7850 \mathrm{~kg} / \mathrm{m}^{3} . E, \nu$ and $\rho$ are, respectively, the elastic modulus, Poisson's ratio and density. Table 3 shows a comparison between the obtained natural frequencies by the developed FEM model and those identified through the experimental setup. 
(a)

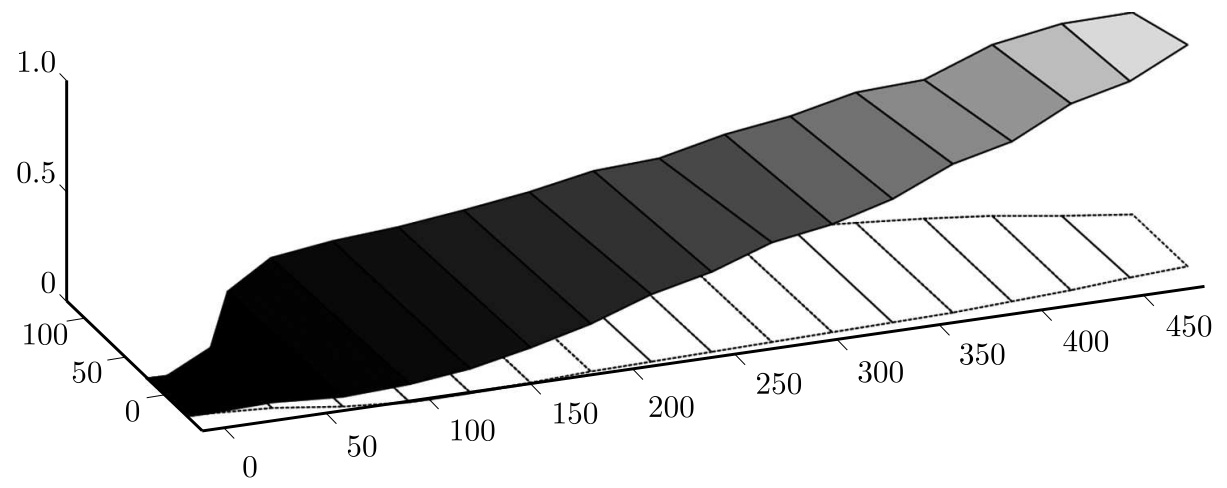

(b)

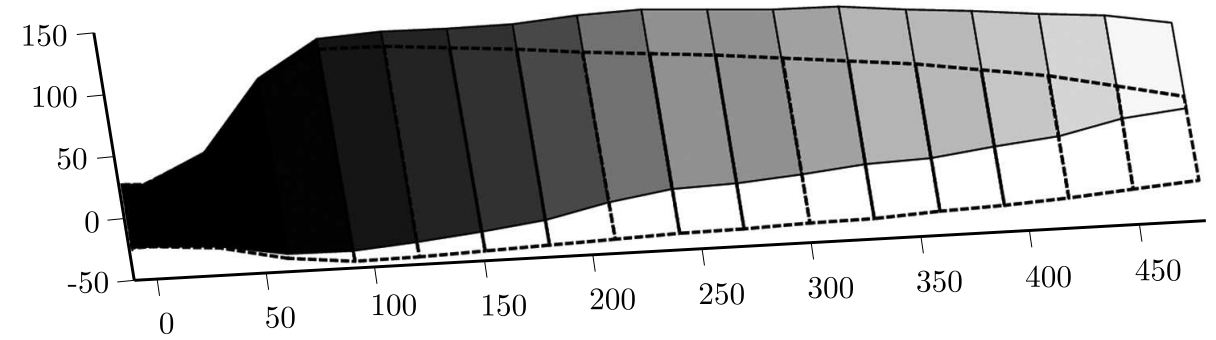

(c)

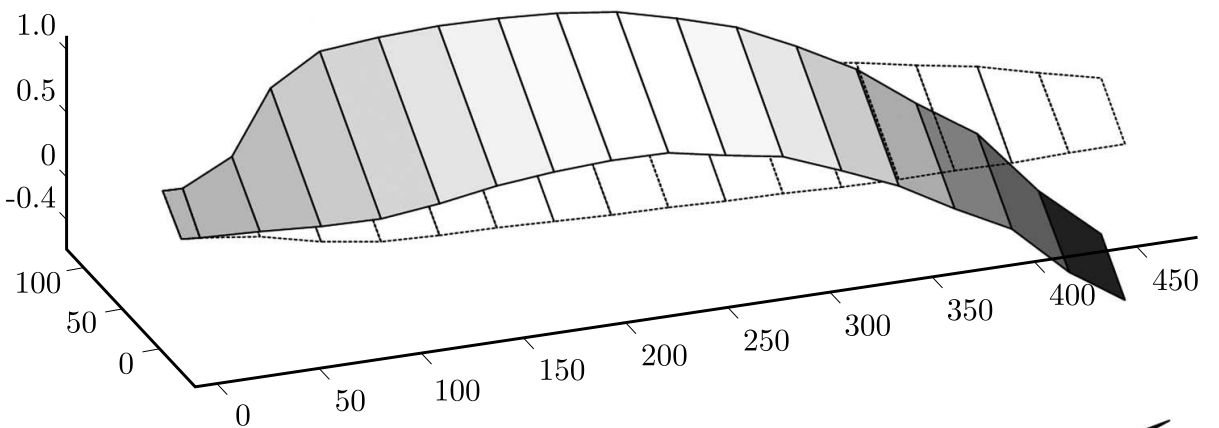

(d) 1.0

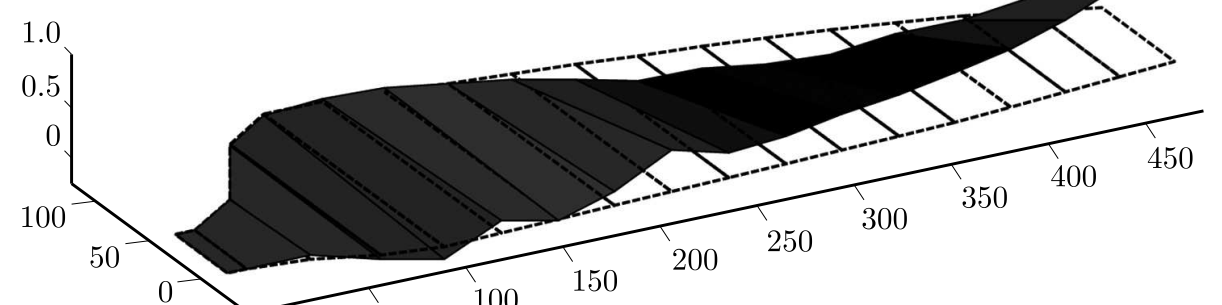

(e)

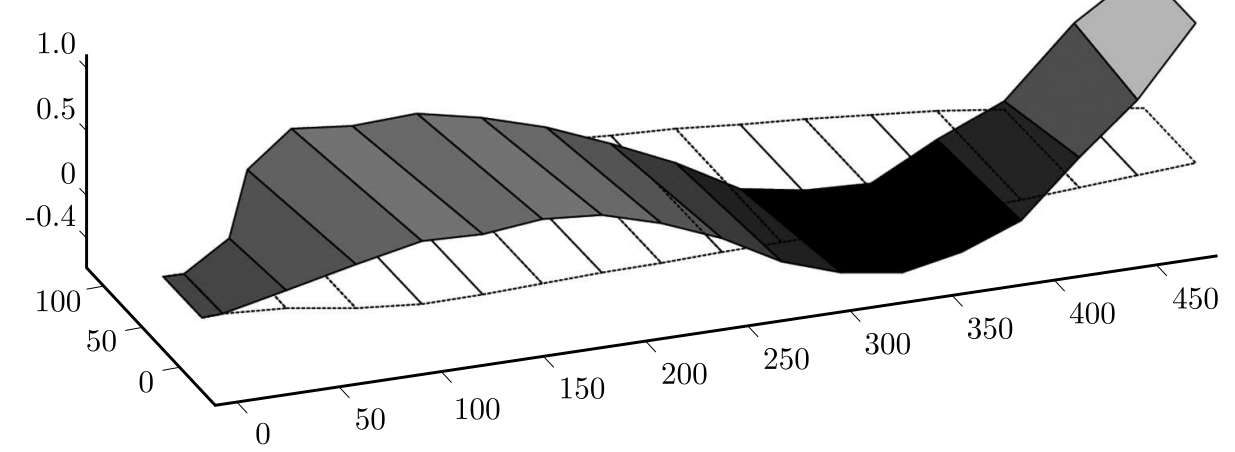

Fig. 9. The segmented blade mode shapes: (a) 1st mode (1st flapwise mode), (b) 2nd mode (1st edgewise mode), (c) 3rd mode (2nd flapwise mode), (d) 4th mode (1st torsional mode), (e) 5 th mode (3rd flapwise mode) 
Table 3. The blade without preload of the threaded shaft: Natural frequencies before adjustment of the elastic modulus

\begin{tabular}{|c|c|c|c|}
\hline Mode order & FEM & Experimental & Diff [\%] \\
\hline \hline 1 & 18.37 & 17.4 & 5.28 \\
\hline 2 & 25.21 & 24.8 & 1.62 \\
\hline 3 & 90.19 & 85.7 & 4.97 \\
\hline 4 & 187.91 & 180.2 & 4.10 \\
\hline 5 & 214.07 & 219.2 & 2.34 \\
\hline
\end{tabular}

To match the elastic modulus of the numerical model with the built model, an iterative process has been done to adjust the first natural frequency obtained by FEM with that obtained from experimental analysis. Thus, the adjusted elastic modulus is $E_{r}=2.25 \mathrm{GPa}$.

Table 4. The blade without preload of the threaded shaft: Natural frequencies after adjustment of the elastic modulus

\begin{tabular}{|c|c|c|c|}
\hline Mode order & FEM & Experimental & Diff [\%] \\
\hline \hline 1 & 17.4 & 17.4 & 0 \\
\hline 2 & 24.19 & 24.8 & 2.45 \\
\hline 3 & 84.25 & 85.7 & 1.69 \\
\hline 4 & 178.79 & 180.2 & 0.78 \\
\hline 5 & 213.71 & 219.2 & 2.5 \\
\hline
\end{tabular}

As long as the maximum difference is about $2.5 \%$, the presented numerical model is validated, at least without the threaded shaft preload effects, and the adjusted elastic modulus puts the numerical model much closer to reality.

\subsection{Threaded shaft preload effects}

To determine the proportional tightening torque coefficient $T_{p}$, a tightening torque $C_{s}=0.6 \mathrm{Nm}$ is applied by the nut. The proportional tightening torque coefficient is determined by adjusting the first natural frequency obtained from the numerical model to that identified through experimental study. Thus, the determined tightening torque coefficient is $T_{p}=1.62$. Table 5 shows the first five natural frequencies determined by the FEM and the experimental study.

Table 5. Natural frequencies of the blade with the threaded shaft preload: $C_{s}=0.6 \mathrm{Nm}$

\begin{tabular}{|c|c|c|c|}
\hline \multirow{2}{*}{ Mode order } & \multicolumn{3}{|c|}{ The threaded shaft preload $C_{s}=0.6 \mathrm{Nm}$} \\
\cline { 2 - 4 } & FEM & Exp & Diff [\%] \\
\hline \hline 1 & 19.5 & 19.5 & 0 \\
\hline 2 & 27.2 & 26.7 & 1.83 \\
\hline 3 & 95.8 & 93.5 & 2.4 \\
\hline 4 & 194.8 & 197.2 & 1.21 \\
\hline 5 & 226.8 & 234.4 & 3.24 \\
\hline
\end{tabular}

To validate the chosen torque proportional coefficient, the second torque $C_{s}=1 \mathrm{Nm}$ is applied.

Table 4 shows that the maximum difference is about $3.62 \%$ between the FEM modeling and the experimental results. So, the assumed stiffness matrix form for the threaded shaft preload is adequate. Furthermore, from Tables 5 and 6 , it is observed that the blade natural frequencies are proportional to the tightening torque. 
Table 6. Natural frequencies of the blade with the threaded shaft preload: $C_{s}=1 \mathrm{Nm}$

\begin{tabular}{|c|c|c|c|}
\hline \multirow{2}{*}{ Mode order } & \multicolumn{3}{|c|}{ The threaded shaft preload $C_{s}=1 \mathrm{Nm}$} \\
\cline { 2 - 4 } & FEM & Exp & Diff [\%] \\
\hline \hline 1 & 23.8 & 24.1 & 1.24 \\
\hline 2 & 31.81 & 30.9 & 2.86 \\
\hline 3 & 113.43 & 110.6 & 2.49 \\
\hline 4 & 214.48 & 207.8 & 3.11 \\
\hline 5 & 243.35 & 252.5 & 3.62 \\
\hline
\end{tabular}

\subsection{Rotating blade frequencies analysis}

Several researchers have investigated the effects of the rotating speed on the blade natural frequencies. However, those researches limited their examinations to simple blade shapes, or they ignored the effects of the segments assembling load. In this study, based on the adjusted numerical model of the segmented shell type wind turbine blade, the natural frequencies are investigated taking into account both the rotation speed and the effects of the segments assembling load.

(a)

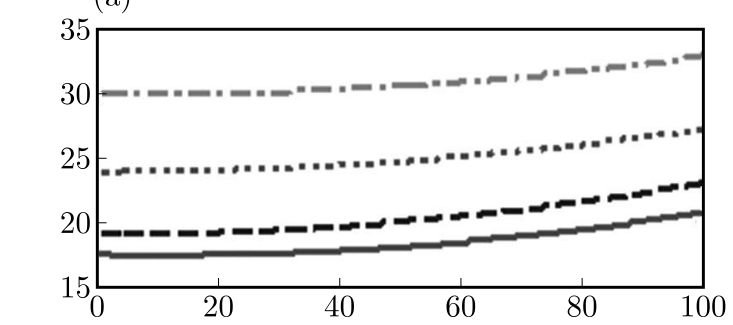

(c)

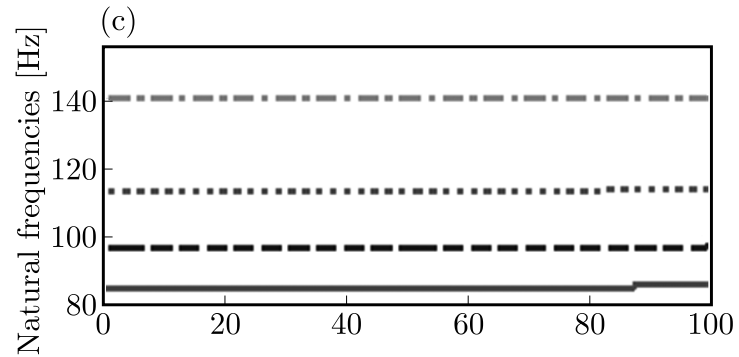

(e) $\cdots \cdots \cdots \cdot C_{s}=1.0 \mathrm{Nm}-\cdot-C_{s}=1.5 \mathrm{Nm}$

(b)

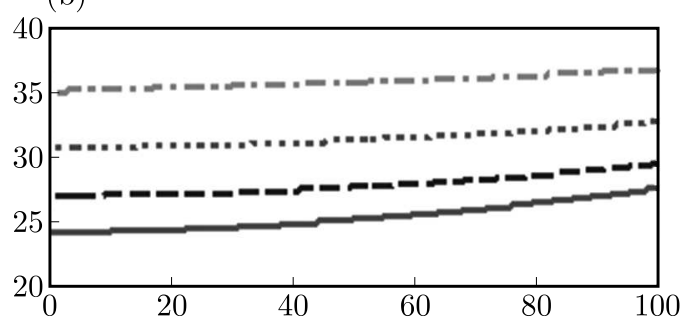

(d)

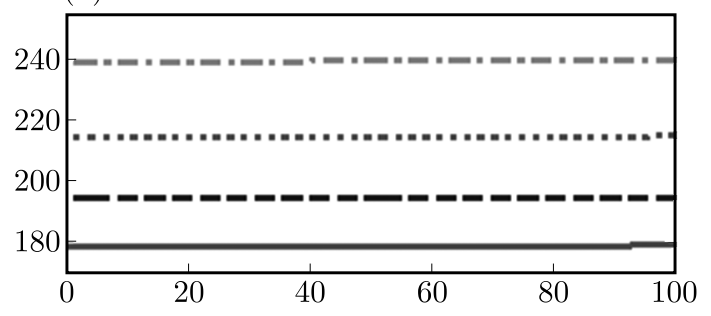

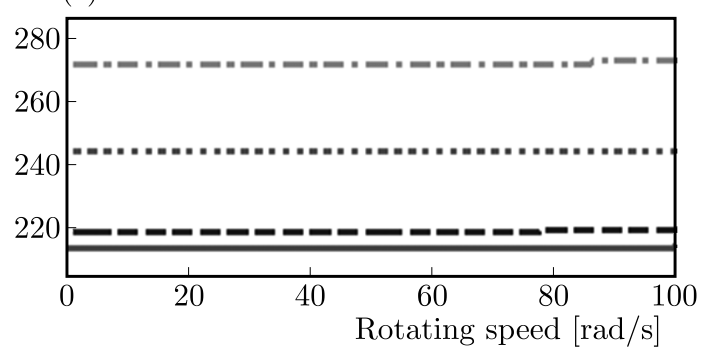

Fig. 10. Natural frequency variation versus rotating speeds for various tightening torque:

(a) 1st natural frequency, (b) 2nd natural frequency, (c) 3rd natural frequency, (d) 4th natural frequency, (e) 5th natural frequency

The segments assembling load influences the rotating blade natural frequencies as illustrated in Fig. 10. Natural frequencies variations maintain the same curve shape for different tightening torque, as regards to the rotating speed increase. Furthermore, an increase in the natural frequencies is clearly affected by the applied tightening torque. Interestingly, the tightening effect on 
modal frequencies is clearly more dramatic than the effects stemming from the blade rotation. From the first two natural frequencies variation curves, it is observed that the additional stiffness generated by the tightening torque attenuates the rotating speed effects on variation of the natural frequencies.

\section{Conclusions}

In this study, natural frequencies and mode shapes of a segmented wind turbine blade have been established by experimental and numerical studies. The segmented blade shape assembled with a threaded shaft and a nut has been modeled using linear triangular shell elements. The proposed numerical model has been adjusted through experimental study to better approach the real system. The identified modal parameters using the ERA method were validated by reconstructing the measured impulse responses and transfer functions. The tightening torque effects on the natural frequencies of a non rotating segmented blade were investigated by experimental means and incorporated into the numerical model to study their influence on the dynamic behavior of the rotating blade. The obtained numerical results present a good correlation with those identified by the experimental study. The results show the increase of the blade natural frequencies of all modes due to increasing tightening torque applied by the nut to assemble the blade segments, in addition to an increase in the rotational speed.

The adjusted numerical method presented in this study can be used to evaluate vibration characteristics of the segmented wind turbine blade with a complex shape, taking into consideration the segments assembly load. This study is limited to the rotation speed and tightening torque effects, and can be extended by taking into account the aerodynamic effect. Interestingly, friction effects between the blade segments will be considered in the future adjustment of the numerical model.

\section{References}

1. Abdulaziz A.H., Elsabbagh A.M., Akl W.N., 2015, Dynamic and static characterization of horizontal axis wind turbine blades using dimensionless analysis of scaled-down models, International Journal of Renewable Energy Research (IJRER), 5, 2, 404-418

2. Bayoumy A.H., Nada A.A., Megahed S.M., 2013, A continuum based three-dimensional modeling of wind turbine blades, Journal of Computational and Nonlinear Dynamics, 8, 3, 031004

3. Bhat C., Noronha D.J., Saldanha F.A., 2015a, Structural performance evaluation of modularized wind turbine blade through finite element simulation, International Journal of Mechanical, Aerospace, Industrial, Mechatronic and Manufacturing Engineering, 9, 6, 930-942

4. Bhat C., Noronha D.J., Saldanha F.A., 2015b, Structural performance evaluation of segmented wind turbine blade through finite element simulation, International Journal of Mechanical, Aerospace, Industrial, Mechatronic and Manufacturing Engineering, 9, 6, 996-1005

5. Branner K., Berring P., Berggreen C., Knudsen H.W., 2007, Torsional performance of wind turbine blades - Part II: Numerical validation, International Conference on Composite Materials (ICCM-16)

6. Broehl J., 2014, Wind Energy Innovations: Segmented Blades, http://www.navigantresearch.com/blog/

7. DhaR S., 2006, Development and validation of small-scale model to predict large wind turbine behavior, Doctoral dissertation, Indian Institute of Technology, Bombay

8. GRIFfith D.T., 2009, Structural dynamics analysis and model validation of wind turbine structures, 50th AIAA/ASME/ASCE/AHS/ASC Structures, Structural Dynamics, and Materials Conference 17th AIAA/ASME/AHS Adaptive Structures Conference 11th AIAA, p. 2408 
9. Ha N.S., VAng H.M., Goo N.S., 2015, Modal analysis using digital image correlation technique: An application to artificial wing mimicking beetles hind wing, Experimental Mechanics, 55, 5, 989-998

10. Hamdi H., Mrad C., Hamdi A., Nasri R., 2014, Dynamic response of a horizontal axis wind turbine blade under aerodynamic, gravity and gyroscopic effects, Applied Acoustics, 86, 154-164

11. Kang H., Chang C., Saberi H., Ormiston R.A., 2014, Assessment of beam and shell elements for modeling rotorcraft blades, Journal of Aircraft, 51, 2, 520-531

12. Kim S.W., Kim E.H., Rim M.S., Shrestha P., Lee I., Kwon I.B., 2011, Structural performance tests of down scaled composite wind turbine blade using embedded fiber Bragg grating sensors, International Journal Aeronautical and Space Sciences, 12, 4, 346-353

13. Larsen G.C., Hansen M.H., Baumgart A., Carlén I., 2002, Modal Analysis of Wind Turbine Blades, Riso National Laboratory, Denmark

14. Maalawi K.Y., Negm H.M., 2002, Optimal frequency design of wind turbine blades, Journal of Wind Engineering and Industrial Aerodynamics, 90, 8, 961-986

15. McKittrick L.R., Cairns D.S., Mandell J., Combs D.C., Rabern D.A., Van Luchene R.D., 2001, Analysis of a composite blade design for the AOC 15/50 wind turbine using a finite element model, Sandia National Laboratories Report

16. MolenaAr D.P., 2003, Experimental modal analysis of a $750 \mathrm{~kW}$ wind turbine for structural model validation. ASME 2003 Wind Energy Symposium, American Society of Mechanical Engineers, $322-339$

17. Park J.H., Park H.Y., Jeong S.Y., Lee S.I., Shin Y.H., Park J.P., 2010, Linear vibration analysis of rotating wind-turbine blade, Current Applied Physics, 10, 2, S332-S334

18. Saldanha F.A., Rao V.V., Christopher J., Adhikari R., 2013, Investigations on concepts for modularizing a horizontal axis wind turbine blade, ASME 2013 International Design Engineering Technical Conferences and Computers and Information in Engineering Conference, pp. V008T12A003-V008T12A003, American Society of Mechanical Engineers

19. Sami S., Zai B.A., Khan M.A., 2014, Dynamic analysis of a 5KW wind turbine blade with experimental validation, Journal of Space Technology, 4, 1, 82-87

20. Sheibani M., Akbari A.A., 2015, Finite element modeling of a wind turbine blade, Journal of Vibroengineering, 17, 7

21. Tartibu L.K., Kilfoil M., Van Der Merwe A.J., 2012, Vibration analysis of a variable length blade wind turbine, International Journal of Advances in Engineering and Technology, 4, 1, 630-639

22. Yangui M., Bouaziz S., Taktak M., Haddar M., El-Sabbagh A., 2016, Nonlinear analysis of twisted wind turbine blade, Journal of Mechanics, doi:10.1017/jmech.2016.120, 1-10 